insistent patients for the Freiburg treatment, by giving them "near" twilight sleep; are courting charlatanry.

Obstetrics appears, as it passes before the mental vision, like a panorama of light and shade. Supposed discoveries in the science and improvements in the art illuminate the scene, till the crucial light of experience casts a shadow of disappointment over the factitious light. We seek the truth. Physicians know too well that the search is surrounded with difficulties, for we advance along the asymptote of the hyperbola; though we have not attained the absolute, we are approaching the object of our quest."

There are still many problems in obstetrics to be solved, including a remedy that will produce amnesia in labor or preferably eutocia, at will - tuto, cito, jucunde, safely, quickly, pleasantly. Meanwhile let us continue to mitigate the pangs of labor with the measures which in succoring the mother do not jeopardize the life of her child.

The keynote to decreasing the appalling infant mortality is good obstetrics, and the watchword is efficiency - efficiency in prenatal care - so that at the time of birth, mother and child shall be in the best possible condition, and efficiency in the conduct of labor, whether it be in the rôle of "watchful waiting" or masterly activity, in order that the child shall be assured its inalienable right to be born alive and healthy, and the mother safeguarded to a successful and happy fruition of her noblest mission in lifematernity.

2426 Pennsylvania Avenue N. W.

\section{WHERE CHIROPRACTORS ARE MADE}

\section{THOMAS F. DUHIGG, M.D.}

DES MOINES, IOWA

As the season for legislation approaches, I feel that the information $I$ have concerning chiropractors should be put at the disposal of those interested in guarding the public health and maintaining respectable educational standards. The chiropractor's machine-made bills will be introduced into the legislature of every state where they have not received recognition.

Iowa schools of chiropractic probably graduate more than the schools of any other three states. Davenport is called the home of this sect; but Iowa does not recognize chiropractors, and they are liable to a fine of $\$ 300$ if they practice here. Obviously they swarm to other states, in some of which they are permitted by law to practice, and in others they are merely tolerated. It strikes us as peculiar that other states, some with high educational standards, should take large consignments of our "graduate" chiropractors who have graduated from schools which require no preliminary qualifications and which have no libraries or hospitals - graduates of schools without any standing, inspected by no one, regulated by no one and conforming only to their own low estimate, which refers entirely to financial and not at all to scientific standards.

After reading the reports of the inspector of the state of Pennsylvania, I believe the forty-seven other states will exclude the graduates of the Iowa schools of chiropractic the same as Pennsylvania has done. This report is remarkable in that it was made by one cutside Iowa and in the interest of the health of the people of a far distant state. It is a testimonial to the care and judgment exercised by the officials of the great commonwealth of Pennsylvania in safeguarding the lives and health of those they are sworn to protect. Likewise it is an indictment of the officials in all those states which have accepted these graduates without first having made a careful inspection and ascertained the extreme wretchedness of the physical equipment of the schools and the mental equipment of their graduates.

The accompanying tabulation gives the reports on the three schools of chiropractic at Davenport, Iowa, made by the inspector of the Pennsylvania Bureau of Medical Education and Licensure.

CHIROPRACTIC COLLEGES OF IOWA

A TABULATION FROM REPORTS OF THE INSPECTOR OF THE PENNSYLVANIA BUREAU OF MEDICAL EDUCATION AND LICENSURE

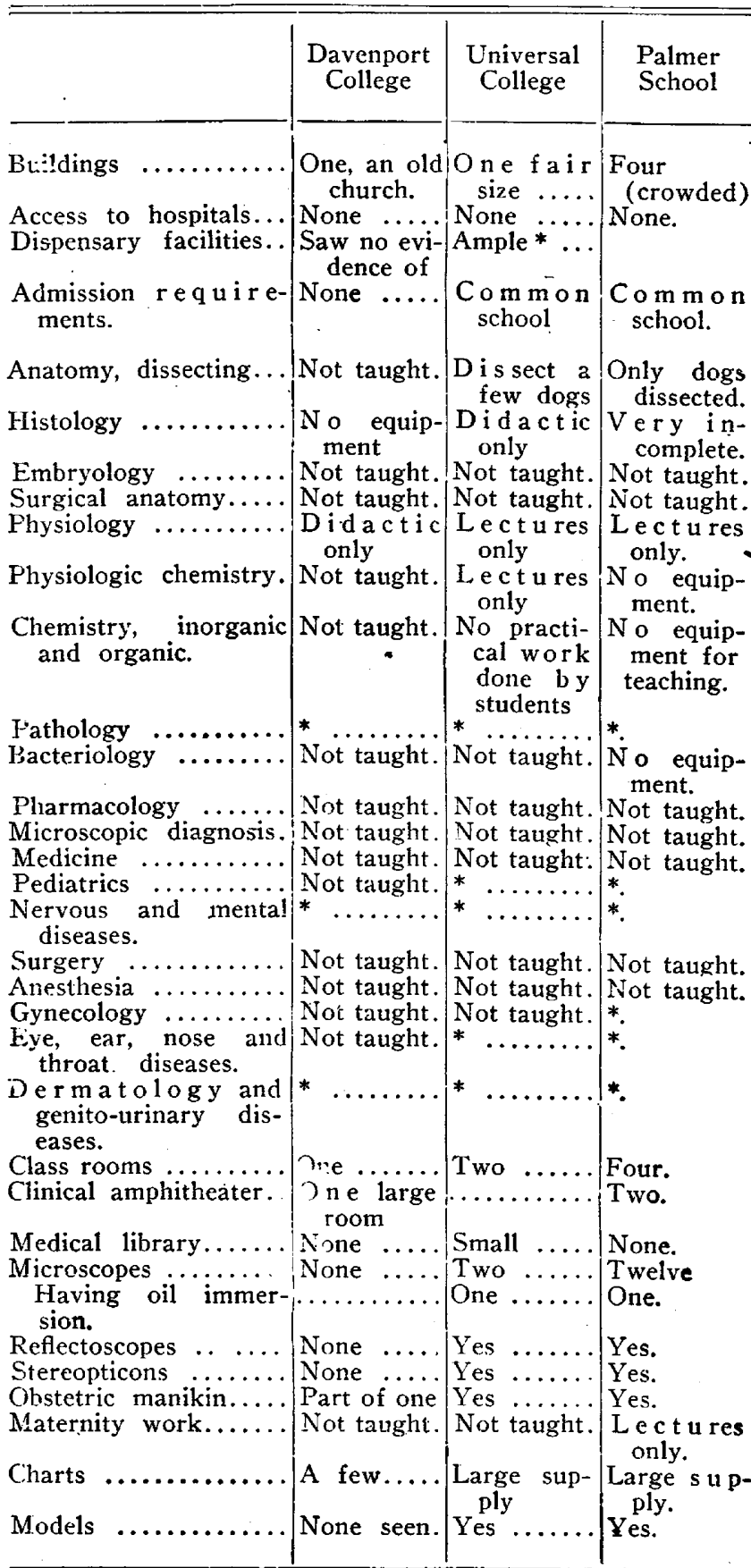

* This subject is taught only from the chiroprattic stand. point, as it is related to certain spinal "lesions." 
Regarding the individual colleges the inspector made the following statements:

Davenport College of Chiropractic.-"Their alleged "chemical laboratory' consisted of a table about 18 inches square, on which were six dusty bottles and three dirty test tubes. There were no records of work done by the students or of attendance at lectures or clinics."

Universal Chiropractic College.- "They are not in any way equipped to give the character of instruction that would make their graduates safe advisers to the sick."

Palmer School of Chiropractic.-."They pretend to give a course in obstetrics with no practical experience. A person who assumed to practice on information gained from this course alone would be dangerously incompetent.

"Some of their professors are exceedingly ignorant. The 'professor' of chemistry alleged he taught the 'Widal test' chemically, but chemicals for even ordinary tests were not in evidence: those in evidence showed no marks of use, most of the bottles being still sealed.

"The institution is not physically equipped to turn out safe graduates."

A letter from Dr. J. M. Baldy, president of the Pennsylvania Bureau of Medical Education and Licensure, to whom the manuscript of this article was submitted, states as follows:

"The data quoted from our inspection is correct. I have gone over it myself and have submitted it to the inspector."

It is sufficient to say that the three schools are uniform on the following points: None has a library, a hospital, a laboratory that is worthy of the name, postmortems or capable teachers. Add to this farce students without preliminary education beyond the mere ability to read and write and who "graduated" after a course of only one year in one of these "colleges," and we have an individual who is hopelessly handicapped for life, one who cannot in any sense be considered a safe adviser of the sick.

These reports set forth everything with painful exactness and embarrassing detail. Any patriotic legislator will be justly incensed at the thought of taking the intellectual refuse from these schools who are not pernitted to practice in Iowa, to be used in his own state as the guardians of life and health. They should not be given legal recognition to practice in any state. If they are permitted to practice, it should be only after they have obtained the same professional and preliminary training that is required of physicians, which in Iowa is a high school education and two years of collegiate work plus four years of professional training in a medical school that maintains a standard satisfactory to the licensing board.

Inconsistency of the Antivivisectionist.-Of course there are all sorts of men among physicians and surgeons as in all o.her professions. Abuses and outrages do occur, no doubt. There have been wicked doctors who have abused their trust; and there have been clergymen with whom the virtue of a young lady boarder was not safe; but we need not say for this reason that all surgeons are arch torturers and that all preachers are arch-lechers. Just as you do not need to pass a special law against adultery by ministers of the gospel, but that if you did so you would put an imputation on the character of a large body of earnest, sincere and unselfish men, so you should not pass laws which would put on men in biological research the imputation of bad faith and cruelty. Make the general laws against cruelty to animals as strict and far-reaching as may seem necessary.for the good of the human race; but do not single out the men who are devoting their lives to the search after that knowledge which is for the best good of the race, and make them the special objects of unnecessary restrictive limitations. If experiments on animals must be prohibited let the same law prohibit castration of animals and the dehorning of cattle. If the English law requiring all operations by a scientific man to be done under anesthesia be adopted, then require that operations on the farm be performed in the same way.--Maxwell, Science.

\section{RECTAL AS A SUBSTITUTE FOR VAGINAL EXAMINATIONS. IN LABOR}

RUDOLPH WIESER HOLMES, M.D.

Associate Professor of Obstetrics and Gynecology, Rush Medical College CHICAGO

In spite of the most rigorous regard to the details of asepsis in the preparation of the patient, of the attendant's hands, and of the supplies which may directly or indirectly approach the two, the dangers of puerperal infection have not been reduced to that negligible degree which our profession should attain. Since the days of Carl Braun, various authorities have recog. nized the dangers accompanying vaginal examinations, have strenuously demanded the diminution of their number, and have sought means whereby such curtailment might be possible. All modern authorities are agreed that vaginal examinations, no matter with what conscientious regard to aseptic technic they are conducted, carry with them their risk of sepsis. Today it is generally recognized that abdominal palpation, aided by a proper interpretation of clinical evidences, offers as much, if not more, certitude as to the condition of the woman and progress of labor than do vaginal examinations alone. The elimination of the necessity of entering the vagina, or at least reducing the frequency to the point at which imperative exigency demands it, will be a distinct obstetric advance. In this paper, I would show that rectal examination fulfils this purpose, and that rectal will secure as much definite information, in most particulars, as do vaginal examinations, and without the risks of infection which inevitably accompany the latter.

When ventral fixation was a popular procedure, I found it expedient, in a number of women in labor, to endeavor to reach the cervix by rectal palpation. This was merely applying a method resorted to in gynecologic cases when, as in virgins, it was impracticable or impossible to use the vaginal route. However, this did not suggest the full value of the method in the conduct of labor. Two or three years ago the broader application was grasped from a source not determined. At first, used in an incidental manner, then as a routine, an experience matured which has convinced me that it was an invaluable method of investigation. Now, I am certain that rectal examination, supplementing abdominal palpation, should largely supersede vaginal touch in the conduct of normal labor, and in certain pathologic cases to be hereinafter mentioned; the latter route should be reserved solely for those cases in which the findings are inconclusive, or as a preliminary to operative work through the parturient canal.

Rectal, as a substitute for vaginal examination, was suggested by Kroenig, ${ }^{1}$ Nov. 20, 1893, in a paper read before the Obstetric Society of Leipzig. The method was introduced in his clinic early in August, 1893. The midwives quickly developed a facility in the procedure, so that in the three months covered by his report, 90 per cent. of all labors were conducted by rectal examination alone. He deduced the following conclusions :

1. Midwives could palpate the spines of the ischia, determine the movability of the coccyx, and estimate the degree of resistance of the perineum.

2. They could determine whether the presenting part were in the pelvis or not.

1. Kroenig: Zentralbl. f. Gynäk., March 10, 192! 